

Cite this: RSC Adv., 2015, 5, 89809
Received 21st July 2015

Accepted 15th October 2015

DOI: $10.1039 / c 5 r a 14470 a$

www.rsc.org/advances

\section{Low cost semi-continuous bioprocess and online monitoring of hydrogen production from crude glycerol}

\author{
Saurabh Jyoti Sarma, ${ }^{a}$ Sampa Maiti, ${ }^{a}$ Satinder Kaur Brar, ${ }^{\text {*a }}$ Yann Le Bihan, ${ }^{\text {b }}$ \\ Gerardo Buelna ${ }^{b}$ and Mausam Verma ${ }^{c}$
}

\begin{abstract}
High process costs arising from expensive media components, hydrogen partial pressure buildup in the head-space of the reactor, sharp decrease in medium $\mathrm{pH}$ due to accumulation of organic acids, substrate inhibition, as well as loss of biomass due to short hydraulic retention times are the major bottlenecks of fermentative hydrogen production. Therefore, the purpose of the present investigation was to develop a process to deal with all these problems at a time. The proposed approach demonstrates enhanced hydrogen production by a low cost process involving crude glycerol (CG), the waste from the biodiesel production process, as the only feedstock. This semi-continuous type of fermentation carried out in a $7.5 \mathrm{~L}$ bioreactor helped to eliminate substrate inhibition with no compromise in cumulative hydrogen production. By controlling product inhibition and the negative effect of by-product accumulation, as well as by preventing the loss of active biomass, a production of $5.18 \mathrm{~L}-\mathrm{H}_{2}$ per L-medium has been achieved. This amount is higher than the 2.02 to $2.68 \mathrm{~L}-\mathrm{H}_{2}$ per $\mathrm{L}$ medium previously reported for CG bioconversion. Reduction of feed CG concentration from $120 \mathrm{~g} \mathrm{~L}^{-1}$ to $60 \mathrm{~g} \mathrm{~L}^{-1}$ was found to improve the glycerol utilization from $65 \%$ to $91 \%$.
\end{abstract}

\section{Introduction}

Being a carbon free fuel and water being the major byproduct of its combustion, if commercially used as a replacement of present fossil derived energy carriers, hydrogen will be able to contribute in greenhouse gas emission reduction. ${ }^{1-3}$ It has a gravimetric energy density of $142 \mathrm{MJ} \mathrm{kg}^{-1}$, which is higher than the common fuels, such as gasoline (47 $\mathrm{MJ} \mathrm{kg}^{-1}$ ) and diesel (43 MJ kg-1).,5 In this context, hydrogen production by environmentally friendly technology, such as bioconversion of biomass carries tremendous industrial opportunity. ${ }^{6,7}$ By using different agro-industrial waste materials as the feedstock, in order to get maximum benefit of the technology, biohydrogen production process can be visualized as a sustainable strategy for organic waste management. Considering this fact, crude glycerol, the major by-product of transesterification process of lipid used for biodiesel production has been evaluated as a substrate for fermentative hydrogen production. In a typical biodiesel production process, production of $100 \mathrm{~kg}$ of biodiesel is accompanied by co-production of nearly $10-11 \mathrm{~kg}$ of CG. ${ }^{8,9} \mathrm{CG}$ is mainly a mixture of different compounds, such as glycerol,

${ }^{a}$ Institut National de la Recherche Scientifique (INRS), Centre Eau, Terre \& Environnement, 490, Rue de la Couronne, Québec(QC), G1K 9A9, Canada. E-mail: satinder.brar@ete.inrs.ca; Fax: +1 418654 2600; Tel: +1 4186543116

${ }^{b}$ Centre de Recherche Industrielle du Québec (CRIQ), Québec (QC), G1P 4C7, Canada ${ }^{c} \mathrm{CO}_{2}$ Solutions Inc., 2300, rue Jean-Perrin, Québec, G2C 1T9, Canada monoglyceride, diglyceride, methanol, soap, and catalysts used for transesterification. Corresponding to increase in global biodiesel production, CG production has also seen a rise. Owing to its increased availability and relatively complex composition, CG price could be as low as $\$ 0.05 /$ pound. ${ }^{10}$ Thus, in addition to environmental benefits, successful application of CG as a feedstock for hydrogen production may serve as a mean of its valorization.

Unfortunately, high process cost is a serious setback to hydrogen production by CG bioconversion. It has been observed that the cost of synthetic media components could be as high as $82 \%$ of total cost of such a process. ${ }^{11}$ Therefore, major objective of present investigation was to develop a highly efficient low cost hydrogen production process using CG as the sole carbon and nutrient source. Substrate inhibition is another serious challenge of CG based biohydrogen production process. For a batch hydrogen production process, $10 \mathrm{~g} \mathrm{~L}^{-1}$ CG has been found to be optimum for hydrogen production. ${ }^{12}$ Corresponding to an increase in initial CG concentration from 10 to 15 and $20 \mathrm{~g} \mathrm{~L}^{-1}$, any significant improvement in hydrogen production has not been observed. ${ }^{12}$ Therefore, by simply doubling the substrate concentration from $10 \mathrm{~g} \mathrm{~L}^{-1}$ to $20 \mathrm{~g} \mathrm{~L}^{-1}$, it was not possible to double the amount of hydrogen production per liter of medium. Such a situation forces to operate the process at relatively low initial substrate concentration, which in turn will increase the process cost by increasing the media volume. Hence, a semi-continuous process has been proposed to 
increase cumulative hydrogen production per liter of medium. A hydrogen sensor has been used for real time monitoring of hydrogen production.

Thus, substrate inhibition, product $\left(\mathrm{H}_{2}\right)$ inhibition, sharp decrease in process $\mathrm{pH}$ due to byproduct accumulation, requirement of large volume of media/water, as well as high process cost are some major challenges in hydrogen production by crude glycerol bioconversion. If a process is developed without considering any one of these factors, it affects overall effectiveness of such process. In order to get maximum benefit of the technology, therefore, all these challenges should be addressed at a time. This is the first report where all these challenges in hydrogen production from crude glycerol have been dealt with in a single process and that is why this article stands apart from any existing literature. In fact, hydrogen yield close to maximum theoretical yield has already been achieved by different investigators. However, scaling up of these technologies to industrial level by an economically viable way is the next big challenge in biohydrogen research. As demonstrated in the present report, certain carefully selected engineering approaches may give a solution to this issue.

\section{Experimental}

\subsection{Microorganism and culture conditions}

A facultative anaerobic bacterium, Enterobacter aerogenes NRRL B-407, was selected for the present study. This known hydrogen producer is a Gram-negative rod-shaped bacterium, which was provided by ARS (USDA, USA). For regular propagation of the microorganism a synthetic culture medium composed of glucose $\left(5 \mathrm{~g} \mathrm{~L}^{-1}\right)$, casein peptone $\left(5 \mathrm{~g} \mathrm{~L}^{-1}\right), \mathrm{KH}_{2} \mathrm{PO}_{4}\left(2 \mathrm{~g} \mathrm{~L}^{-1}\right)$, $\mathrm{MgSO}_{4} \cdot 7 \mathrm{H}_{2} \mathrm{O}\left(0.5 \mathrm{~g} \mathrm{~L}^{-1}\right)$ and yeast extract $\left(0.5 \mathrm{~g} \mathrm{~L}^{-1}\right)$, has been used. The same culture medium has also been used for inoculum preparation for the present study. For both the purposes, the microorganism was anaerobically grown in $50 \mathrm{~mL}$ of aforementioned medium taken in $125 \mathrm{~mL}$ serum bottles. Prior to inoculation, the bottles were sterilized and cooled to room temperature. After inoculation, the bottles were incubated by using an orbital shaker incubator operated at $30 \pm 1{ }^{\circ} \mathrm{C}$ and 150 $\mathrm{rpm}$. About $5 \%(\mathrm{v} / \mathrm{v})$ of freshly grown microbial culture obtained by this method was used as the inoculum for all hydrogen production studies conducted during this investigation.

\subsection{Crude glycerol as feedstock}

As already mentioned, CG, a by-product of biodiesel manufacturing process has been used as the feedstock for this investigation. The CG has been supplied by Rothsay biodiesel, Canada. ${ }^{13}$ Considering the fact that CG is an industrial waste of very crude nature and a good source of nutrient for microbial growth as well; it is highly possible that it contains different microorganisms. Thus, to have an idea about the activity of its indigenous microbial community, crude glycerol was analyzed to detect potential metabolites of microbial origin. For this purpose, a solution of $12 \mathrm{~g} \mathrm{~L}^{-1}$ of CG was prepared with distilled water and centrifuged at $10000 \mathrm{rpm}(6708 \times g)$ for 10 minutes.
The supernatant was directly analyzed by gas chromatography following the method described in analysis section.

\subsection{Hydrogen production using a $7.5 \mathrm{~L}$ bioreactor}

A 7.5 L bioreactor (Labfors, Infors-HT, Switzerland) with maximum working volume of $5 \mathrm{~L}$ has been used for the present hydrogen production study. Purpose of this study was to develop a low cost bioprocess for hydrogen production by replacing expensive synthetic fermentation media components; therefore, the media were prepared using only CG and water. The first batch of experiment was performed with a medium volume of $3 \mathrm{~L}$ and the initial CG concentration was $10 \mathrm{~g} \mathrm{~L}^{-1}$, whereas, the feeding CG concentration was $60 \mathrm{~g} \mathrm{~L}^{-1}$. The $\mathrm{pH}$ was adjusted with $\mathrm{HCl}$ and $\mathrm{NaOH}$. The fermenter vessels containing medium, feeding bottle with CG solution and acid and base containing bottles were autoclaved for 20 minutes at $121 \pm$ $1{ }^{\circ} \mathrm{C}$. Throughout the fermentation period, agitation of the process was kept constant at $100 \mathrm{rpm}$. All openings of the bioreactor vessel were sealed and the medium was inoculated by transferring the inoculum from serum bottle by using a peristaltic pump fitted with sterile silicone tube.

During the fermentation period, the bioreactor was connected to a laptop where real time values of all process parameters were recorded by using Iris software (Infors-HT, Switzerland). For first 8 hours, the reactor was operated in batch mode. From 8 to 48 hours, CG solution taken in feeding bottle was drop wise added to main fermentation medium and equal amount of fermented medium was taken out by using a peristaltic pump, so that the medium volume of the bioreactor remains constant at $3 \mathrm{~L}$. Another purpose of withdrawing the fermented medium from the reactor was to remove a portion of the organic acids accumulated during the process, so that decrease in medium $\mathrm{pH}$ could be minimized. The reactor was constantly monitored and once the hydrogen concentration in the headspace reached around $30-35 \%(\mathrm{v} / \mathrm{v})$, the medium was bubbled with nitrogen gas to drive away accumulated biogas.

Same procedure was followed for the second batch of experiment with two major exceptions. Firstly, the load of CG used as feed was twice to that of the first batch. Secondly, drop wise addition of the feed was started at 8 hour and it lasted until 72 hours, in contrast to 48 hours in the first case. The reason behind sustained delivery of feed was to avoid probable substrate inhibition due to sharp increase in glycerol concentration in the medium.

\subsection{Analysis}

2.4.1. Hydrogen analysis. A hydrogen sensor was used for online monitoring of hydrogen production in the bioreactor. The sensor used for the present investigation was supplied by BlueSens gas sensor GmbH (Germany). It was installed outside the bioreactor and its inlet was connected to the exhaust gas condenser by using a short tube. Before starting the fermentation, the sensor was connected to power supply for one hour. Following this heating-up time, nitrogen gas was bubbled through the medium for 30 minutes and exhaust gas $\left(\mathrm{N}_{2}\right)$ was allowed to pass through the sensor inlet. During fermentation, 
the outlet of the sensor was closed by multiple layers of paraffin films. After inoculation the sensor started displaying signal in the monitor and it was recorded online.

Crude glycerol contains glycerol and other things such as free fatty acids and soap. While using crude glycerol as the feedstock, often hydrogen produced from the compounds other than glycerol was not considered in most of the hydrogen yield calculations available in the literature. Therefore, to avoid any mistake in the calculation, in the present manuscript instead of hydrogen yield ( $\mathrm{mmol}-\mathrm{H}_{2}$ produced per mol glycerol), hydrogen production has been reported as $\mathrm{mmol}-\mathrm{H}_{2}$ per $\mathrm{L}$ medium or L$\mathrm{H}_{2}$ per L medium.

2.4.2. Analysis of different fermentation end products. Aqueous samples collected at the end of each batch of fermentation were analyzed by GC to determine the amount of different by-products produced during the process. The samples were centrifuged for 10 minutes at $10000 \mathrm{rpm}(6708 \mathrm{~g})$ and the supernatants were directly analyzed by GC (GC7890B, Agilent Technologies, USA). The detector used for this purpose was flame ionization detector (FID). The column temperature gradient used for this analysis was $50-250{ }^{\circ} \mathrm{C}$. It was achieved by increasing the temperature at a rate of $20{ }^{\circ} \mathrm{C}$ per minute. Nitrogen was used as carrier gas. The injection volume was 0.8 $\mu \mathrm{L}$ and iso-butanol was mixed with all samples as internal standard.

2.4.3. Glycerol analysis. At the end of each batch of fermentation $(120 \mathrm{~h})$, liquid samples were collected from the reactor as well as from the effluent collecting bottles and analyzed for residual glycerol concentration. A method originally proposed by Bondioli et al. (2005) has been used for this analysis. ${ }^{\mathbf{1 4}, 15}$ Briefly, $1 \mathrm{~mL}$ of the sample already diluted with distilled water was mixed with $1 \mathrm{~mL}$ of working solution (ethanol, 47.5\% v/v). Subsequently, $1.2 \mathrm{~mL}$ of 'stock solution A' ( $0.2 \mathrm{M}$ acetylacetone solution prepared using a mixture of equal volume of $1.6 \mathrm{M}$ acetic acid and $4.0 \mathrm{M}$ ammonium acetate) and $1.2 \mathrm{~mL}$ of 'stock solution B' (10 mM sodium periodate solution prepared using a mixture of equal volume of $1.6 \mathrm{M}$ acetic acid and $4.0 \mathrm{M}$ ammonium acetate) were added. Further, the test tube containing the final solution was heated at $70 \pm 1{ }^{\circ} \mathrm{C}$ for 1 min by using a rotary shaker water bath and subsequently transferred to a cold water container maintained at $20 \pm 1{ }^{\circ} \mathrm{C}$, until analyzed. The optical density of the reaction mixture was measured at $410 \mathrm{~nm}$ by a UV-Vis spectrophotometer (Carry 100 Bio®, Varian USA). ${ }^{16}$

\section{Results and discussion}

\subsection{Crude glycerol characterization}

The CG used in the present study has been characterized and glycerol content and $\mathrm{pH}$ were found to be $23.63 \pm 2.5 \%(\mathrm{w} / \mathrm{w})$ and 3.4 (at $24 \pm 0.5{ }^{\circ} \mathrm{C}$ ), respectively. ${ }^{12}$ Likewise, elemental analysis has shown that it contains nearly $35.9 \pm 0.4 \%(\mathrm{w} / \mathrm{w})$ of total organic carbon and $3.25 \pm 0.1 \%(\mathrm{w} / \mathrm{w})$ of nitrogen. ${ }^{12} \mathrm{~A}$ detailed characterization of the CG used in the present study could be found in Sarma et al. (2013). ${ }^{12}$ On a similar note, presence of soap, methanol, mono-glyceride, di-glyceride, fatty acid methyl esters, and free fatty acids in CG has been reported. ${ }^{17,18}$ As a part of present investigation, microbial metabolites' presence in CG has been studied. A gas chromatogram of the CG used in the present study has been presented in Fig. 1. From this chromatogram, it is evident that acetone (1.34 $\mathrm{g} \mathrm{kg}^{-1}$ ), butanol (3.38 $\left.\mathrm{g} \mathrm{kg}^{-1}\right)$, ethanol (4.47 $\mathrm{g}$ $\mathrm{kg}^{-1}$ ) and butyric acid were present in CG. This observation indicated that while storing, indigenous microorganism of CG can carry out anaerobic acetone-butanol-ethanol type fermentation; however, presence of these metabolites does not give any direct information about the exact species of the microorganisms present in CG. Anaerobic acetone-butanol-ethanol type fermentation is highly possible because CG is very viscous in nature and hence limited oxygen mass transfer may occur while storing. Thus, local anaerobic/anoxic condition may prevail, once the dissolved oxygen of CG is consumed by indigenous aerobes/facultative anaerobes. As shown in Fig. 1, apart from the compounds identified by the gas chromatographic analysis, there are certain other compounds which could not be identified. Therefore, further characterization can be considered to identify all the compounds present in crude glycerol.

\subsection{Hydrogen production using a $7.5 \mathrm{~L}$ bioreactor}

Effect of different initial CG concentrations, ranging from 2.5$20 \mathrm{~g} \mathrm{~L}^{-1}$, on biohydrogen production had been investigated using small scale batch processes. ${ }^{12}$ The outcome of the study had suggested that $10 \mathrm{~g} \mathrm{~L}^{-1}$ CG was optimum for batch fermentation. Moreover, at relatively high initial CG concentration of $20 \mathrm{~g} \mathrm{~L}^{-1}$, almost $40 \%$ of glycerol was found to remain unutilized. $^{12}$ On the contrary, for large-scale production of biohydrogen, a process with high substrate concentration will be more appropriate as, from stoichiometric point of view; such process will be able to produce more amount of hydrogen per liter of medium. Thus, using same reactor volume, same operating cost and at the expense of almost same amount of energy; more amount of hydrogen could be produced by such process. However, substrate inhibition is a limitation of fermentative hydrogen production ${ }^{\mathbf{1 9 2 0}}$ and as mentioned earlier, when initial CG concentration was increased beyond $10 \mathrm{~g} \mathrm{~L}^{-1}$, almost no improvement in hydrogen production was observed. ${ }^{12}$ This finding has been supported by the report of reduced hydrogen yield at higher glycerol concentration. ${ }^{21}$

In order to overcome the substrate inhibition, therefore, as a part of present study, a semi continuous process has been tested. Two batches of fermentation have been carried out to evaluate the effect of two different feed concentrations, i.e. $60 \mathrm{~g}$ $\mathrm{L}^{-1}$ and $120 \mathrm{~g} \mathrm{~L}^{-1}$ of CG. For the first set of experiment involving $60 \mathrm{~g} \mathrm{~L}^{-1}$ of CG as feed; for initial 8 hours, the fermentation was carried out in batch mode with an initial CG concentration of 10 $\mathrm{g} \mathrm{L}^{-1}$. After utilization of a portion of the feedstock, from 8 to 48 hours, by using a peristaltic pump the CG solution containing $60 \mathrm{~g} \mathrm{~L}^{-1}$ of CG was drop wise added into the fermenter. To keep the medium volume constant, equal volume of fermented medium was simultaneously taken out of the reactor (Fig. 2). The result of this experiment has been presented in Fig. 3. As it is evident from Fig. 3, with a negligible lag period of around 2-3 hours, rate of hydrogen production was almost constant until 


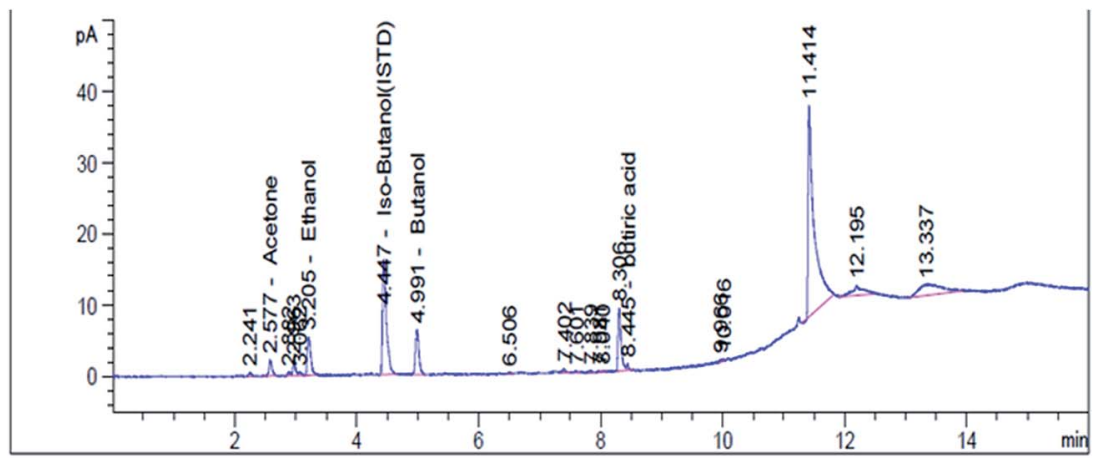

Fig. 1 Gas chromatogram of CG showing the presence of acetone, butanol, ethanol and butyric acid as well as different unidentified compounds.

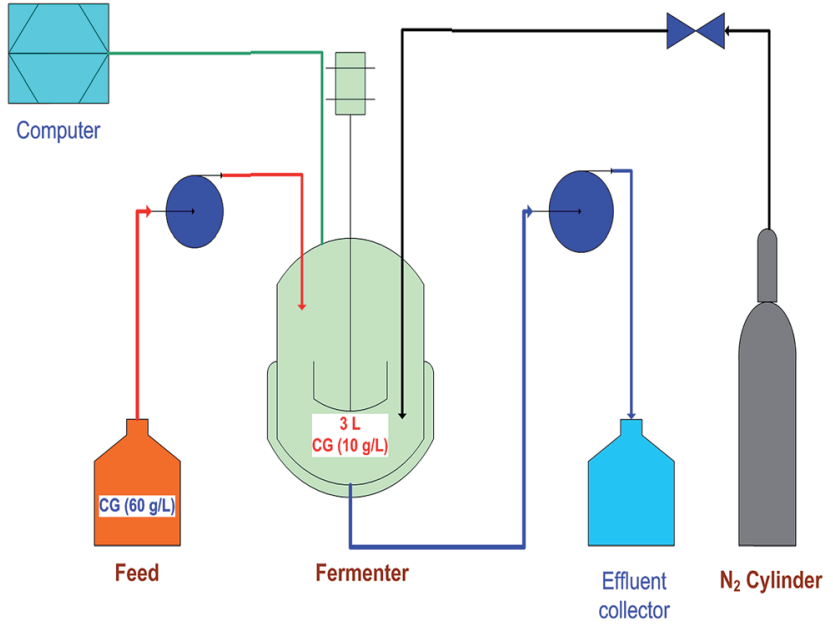

Fig. 2 Schematic representation of the process considered in the present investigation.

48 hours of fermentation. A gradual decrease in hydrogen production rate has been observed after this period; although the production was not stopped even at the end of the experiment. After 48 hours the microbial cells may enter stationary and declining phase of growth, therefore, gradual decrease in hydrogen production observed after this period can be attributed to such phase change. Based on the data recorded online, cumulative hydrogen production has been calculated to be $14.41 \mathrm{~L}$, which corresponded to $4.80 \mathrm{~L}$ hydrogen per $\mathrm{L}$ medium. At atmospheric pressure and $30{ }^{\circ} \mathrm{C}$, this value is equivalent to $190 \mathrm{mmol}-\mathrm{H}_{2}$ per $\mathrm{L}$ medium. For this calculation, fermented medium taken out of the reactor and the amount of hydrogen accumulated in the headspace of bottle that had been used to collect that liquid, have not been considered.

Compared to a traditional batch process, a process of this kind may be able to utilize double amount of CG without doubling the medium volume, and inoculum requirement of the process. Additionally, as only $500 \mathrm{~mL}$ of fermented medium was taken out of the reactor, loss of active biomass should not be as high as a continuous process with short hydraulic retention time. Moreover, the chance of substrate inhibition was lesser, as the process was started at an optimum initial CG concentration $\left(10 \mathrm{~g} \mathrm{~L}^{-1}\right)$ and additional amount of $\mathrm{CG}$ was fed to the process over a period of 40 hours, so that the microorganism gets sufficient time to consume a significant amount of the feedstock. The feeding rate was arbitrarily chosen for this investigation and hence as described in the literature ${ }^{22}$ better process performance could be expected by optimization of this parameter.

Interestingly, corresponding to increase in initial CG concentration of a batch process from $2.5 \mathrm{~g} \mathrm{~L}^{-1}$ to $20 \mathrm{~g} \mathrm{~L}^{-1}$,

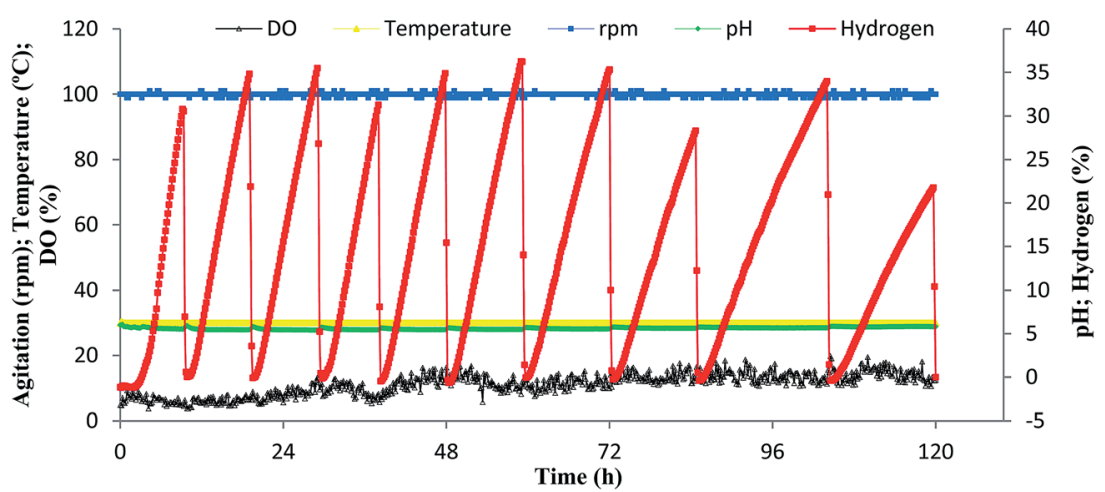

Fig. 3 Online data collected from the first batch of fermentation carried out using a feed CG concentration of $60 \mathrm{~g} \mathrm{~L}^{-1}$. Hydrogen accumulated in the headspace of the reactor was periodically removed by bubbling with nitrogen gas. 


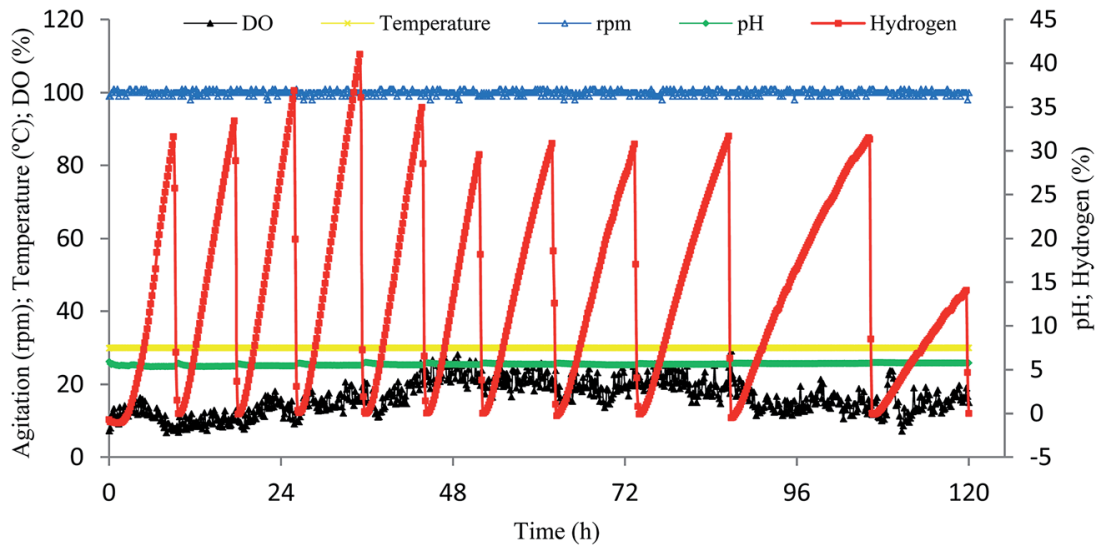

Fig. 4 Online data collected from the second batch of fermentation carried out using a feed CG concentration of $120 \mathrm{~g} \mathrm{~L}{ }^{-1}$. Hydrogen accumulated in the headspace of the reactor was periodically removed by bubbling with nitrogen gas.

Table 1 Summary of the present investigation

\begin{tabular}{lll}
\hline CG concentration in feed $\left(\mathrm{g} \mathrm{L}^{-1}\right)$ & 60 & 120 \\
\hline Amount of glycerol added to the process (g) & 14.17 & 21.26 \\
Amount of unused glycerol (g) & 1.24 & 7.44 \\
$\begin{array}{l}\text { Glycerol utilization (\%) } \\
\text { Cumulative hydrogen production (L) }\end{array}$ & 14.41 & 65 \\
$\begin{array}{l}\text { Hydrogen production per liter medium } \\
\text { (mmol) }\end{array}$ & 190 & 210 \\
$\begin{array}{l}\text { Mol- } \mathrm{H}_{2} \text { produced per mol-glycerol consumed } \\
\text { a } \mathrm{H}_{2} \text { produced from glycerol and other compounds present in crude } \\
\text { glycerol. }\end{array}$ & $4.06^{a}$ & $4.19^{a}$ \\
\end{tabular}

gradual decrease in final media $\mathrm{pH}$ had been observed. ${ }^{\mathbf{1 2}}$ Therefore, sharp decrease in media $\mathrm{pH}$ could be one of the reasons of reduced hydrogen production at high initial substrate concentration. Thus, this observation suggested the fact that by controlling the process $\mathrm{pH}$, higher hydrogen yield could be possible even at relatively high initial CG concentration, such as $20 \mathrm{~g} \mathrm{~L}^{-1}$. Based on this observation; optimum $\mathrm{pH}$ for hydrogen production ( $\mathrm{pH}$ 6) was maintained throughout the fermentation by using $\mathrm{NaOH}$ solution.

The fermentation medium was periodically bubbled with nitrogen gas to remove accumulated hydrogen. According to a report, hydrogen partial pressure buildup in the headspace can adversely affect the product yield. ${ }^{23}$ The authors have demonstrated that nitrogen sparging can increase hydrogen production by removing the gas accumulated in the headspace of the reactor. ${ }^{23}$ For industrial scale production of biohydrogen, periodic nitrogen sparging approach may not be suitable. In such cases, instead of nitrogen sparging, simultaneous production and recovery of hydrogen could be a viable option for enhanced hydrogen yield.

Application of expensive media components reduces the economic feasibility of fermentative hydrogen production. ${ }^{\mathbf{1 1}}$ Likewise, substrate pretreatment is an additional step for hydrogen production using certain substrates, such as lignocellulosic materials. ${ }^{24-26}$ Therefore, in order to develop a low cost process, untreated CG has been evaluated as the only medium component for hydrogen production. The outcome of the study has suggested that the present approach can offer a low cost as well as high yield process for fermentative hydrogen production.

Hydrogen production profile of the second batch of fermentation carried out using the feed containing $120 \mathrm{~g} \mathrm{~L}^{-1}$ of CG, has been presented in Fig. 4. Cumulative hydrogen production was $15.55 \mathrm{~L}$; which corresponded to $5.18{\mathrm{~L}-\mathrm{H}_{2}}_{2}$ per Lmedium. Compared to reported 2.02, 2.5 and $2.68{\mathrm{~L}-\mathrm{H}_{2}}_{2}$ per Lmedium, hydrogen production achieved in the present investigation is significantly higher than all the previous reports (Table 2) involving CG. ${ }^{12,27}$ This value is equivalent to $210 \mathrm{mmol}^{-\mathrm{H}_{2}}$ per L-medium, which is slightly higher than $190 \mathrm{mmol}^{-\mathrm{H}_{2}}$ per Lmedium obtained for the first batch of fermentation carried out using $60 \mathrm{~g} \mathrm{~L}^{-1}$ of CG as feed.

In order to have an idea about substrate utilization, residual glycerol concentrations were determined for each batch of fermentation and the results have been summarized in Table 1. From Table 1, it is evident that in the case of first batch of fermentation using $60 \mathrm{~g} \mathrm{~L}^{-1} \mathrm{CG}$ as feed; almost $91 \%$ of glycerol added to the process has been utilized. On the contrary, corresponding to an increase in feed CG concentration to $120 \mathrm{~g} \mathrm{~L}^{-1}$, glycerol utilization has been reduced to $65 \%$. These observations underline the fact that hydrogen production could be slightly enhanced by increasing the feed CG concentration; however, a considerable amount of glycerol was left unutilized by the approach. As shown in Table $1, \mathrm{H}_{2}$ yield for the first batch was $4.06 \mathrm{~mol} \mathrm{~mol}^{-1}$-glycerol consumed, whereas for the second batch it was $4.19 \mathrm{~mol} \mathrm{~mol}^{-1}$-glycerol consumed. However, as mentioned in Section 2.4.1, in addition to glycerol, some other compounds present in crude glycerol such as soap, free fatty acid etc. could also be simultaneously consumed by the microorganism and they might contribute in final hydrogen yield. Therefore, actual hydrogen production from each mol of glycerol will be slightly lower than these values.

During hydrogen production by microbial fermentation different metabolites are accumulated in the medium as byproducts. Amount of such byproducts produced during the 


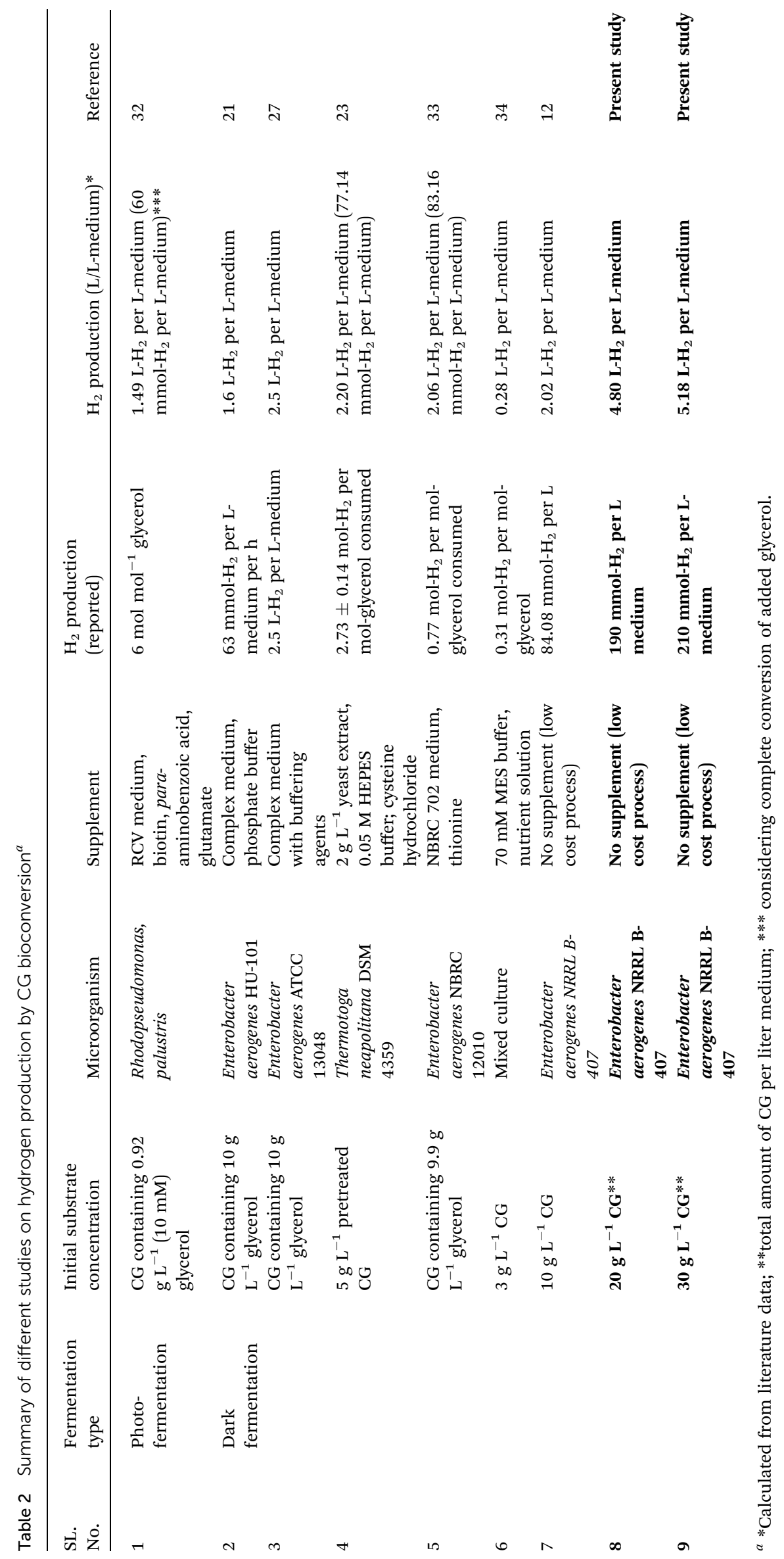


two batches of fermentation has been presented in Fig. 5. From Fig. 5 it is evident that in the case of first batch among acetone (4.9 $\mathrm{mg} \mathrm{L}^{-1}$ ), butanol (10.61 $\mathrm{mg} \mathrm{L}^{-1}$ ), ethanol (317.03 $\mathrm{mg} \mathrm{L}^{-1}$ ), ethanol was the dominant byproduct. In the case of second batch apart from acetone $\left(3.43 \mathrm{mg} \mathrm{L}^{-1}\right)$ and butanol $(4.61 \mathrm{mg}$ $\left.\mathrm{L}^{-1}\right)$, comparatively higher amount ethanol $\left(599.22 \mathrm{mg} \mathrm{L}^{-1}\right)$ as well as acetic acid $\left(77.56 \mathrm{mg} \mathrm{\textrm {L } ^ { - 1 }}\right)$ was produced. Substrate concentration is a parameter to determine the amount and type of byproducts produced during fermentative hydrogen production because it may alter the redox balance of the medium. Therefore, observed differences in byproduct profiles of the two batches of fermentation can be attributed to different feed CG concentrations $\left(60 \mathrm{~g} \mathrm{~L}^{-1}\right.$ and $\left.120 \mathrm{~g} \mathrm{~L}^{-1}\right)$ used in this investigation.

\subsection{Cost benefits analysis}

In Table 3, the items required for and the cost involved in hydrogen production from $1 \mathrm{~kg}$ of crude glycerol by using the semi-continuous process considered in this study has been listed. For a detailed methodology of cost calculation, Sarma et al. (2013) can be consulted. ${ }^{11}$ Based on this estimation, total cost involved in bioconversion of $1 \mathrm{~kg}$ of CG was found to be $\$ 5.9$. Notably, out of this amount, $\$ 4.61$ is for the synthetic medium components required for inoculum development.

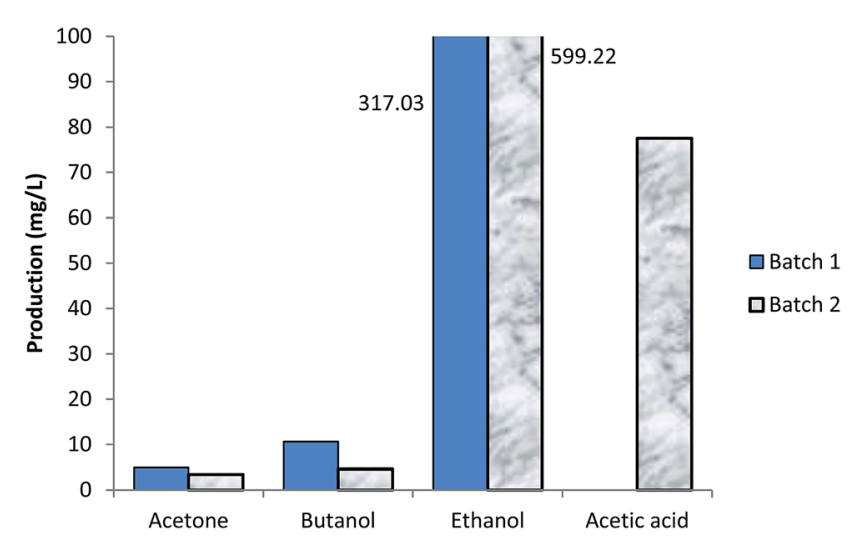

Fig. 5 Different byproducts accumulated in the media after 120 hours of fermentation. Ethanol has been identified as the major by-product of hydrogen production by CG bioconversion.
Interestingly, we have found that a mixture of $5 \mathrm{~g} \mathrm{~L}^{-1}$ crude glycerol and $8 \%(\mathrm{v} / \mathrm{v})$ brewery waste hydrolysate can be used for inoculum development with no compromise in hydrogen production. Thus, inoculum development will be possible without these expensive chemicals and the cost involved in the process will be negligible. Hence, cost involved in hydrogen production can be calculated to be around $\$ 1.29 \mathrm{~kg}^{-1}$ CG. It implies that production of 1 cubic meter of hydrogen will cost around \$5.39. This amount is approximately 53 times lower than a traditional process for CG bioconversion. ${ }^{\mathbf{1 1}}$ Current market value of industrial grade hydrogen is $\$ 7.75$ to $\$ 11.50$ per cubic meter. ${ }^{28}$ Therefore, as an industrial gas, commercial production of biohydrogen seems to be an achievable target. Moreover, the wastewater of hydrogen production process can be directly used for methane generation, ethanol recovery or as phosphate solubilizer..$^{21,29,30}$ Recovery of another biofuel (ethanol) from this wastewater may contribute in overall energy gain of the process. ${ }^{31}$ Further, these potential byproducts may be helpful in further reduction of the process cost by generating additional revenue. For the present analysis, the amount of nitrogen used for flushing out the hydrogen accumulated in the headspace of the reactor was not considered. In industrial scale, instead of using nitrogen, continuous removal of accumulated gas by pump and simultaneous purification by pressure swing adsorption technology could be considered. Likewise, the infrastructure required for the entire production and purification process will also have a contribution in final production cost. It was observed that fermentation medium cost can be as high as $82 \%$ of total cost of hydrogen production from crude glycerol. ${ }^{11}$ Therefore, as shown in Table 3, the cost of only medium ingredients and some other major cost contributors were considered for the present estimation. Thus, actual production cost will be slightly different from the value obtained in this estimation. In fact, a pilot scale study will be more appropriate for cost benefit analysis of biohydrogen production process; however, it was beyond the scope of the present investigation. Additionally, it must be mentioned that to be an effective replacement of fossil fuels, further reduction of biohydrogen production cost will be needed. Therefore, apart from process optimization; possible government subsidies will also be important for economic feasibility of biohydrogen based economy.

Table 3 Cost analysis of the semi-continuous process considered in the present study

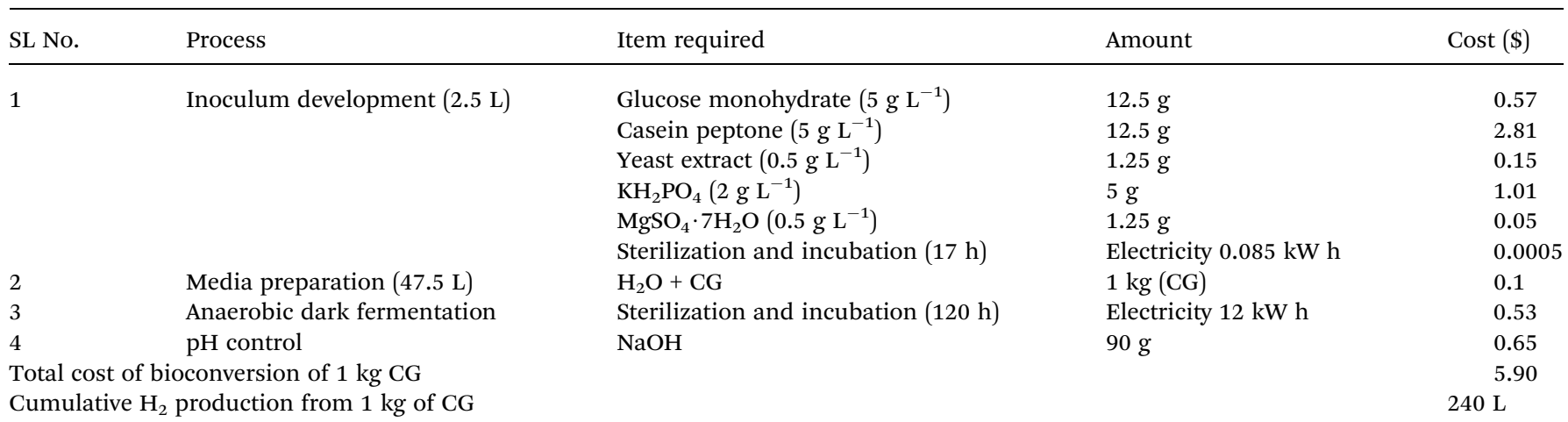




\section{Conclusions}

Acetone, butanol and ethanol have been detected in CG used as the feedstock for present hydrogen production study. The finding indicates that due to cumulative activity of indigenous microorganisms while storing, acetone-butanol-ethanol (ABE) fermentation occurs in CG. Present investigation has demonstrated that by diluting with distilled water, CG can be used as the only medium component to design a low-cost process for enhanced hydrogen production. As high as $5.18{\mathrm{~L}-\mathrm{H}_{2}}$ per Lmedium, which is equivalent to $210 \mathrm{mmol}^{-\mathrm{H}_{2}}$ per L-medium; has been produced by the approach outlined in the present report. This amount is significantly higher than 2.02 to $2.68 \mathrm{~L}$ $\mathrm{H}_{2}$ per L-medium known for hydrogen production by CG bioconversion. Ethanol was the major byproduct of the hydrogen production process. By reducing the feed CG concentration from $120 \mathrm{~g} \mathrm{~L}^{-1}$ to $60 \mathrm{~g} \mathrm{~L}^{-1}$, glycerol utilization could be improved from $65 \%$ to $91 \%$. Overall, it has been concluded that a process where CG is diluted with only water to reduce the process cost, substrate inhibition is minimized by operating the process at optimum CG concentration which is followed by drop wise addition of feed to ensure maximum CG utilization per liter working volume of the fermenter per unit of time, inhibition of hydrogen production by increased hydrogen partial pressure buildup in the headspace of the fermenter is reduced by removing the accumulated gas, $\mathrm{pH}$ of the process is precisely controlled by a low cost option such as addition of $\mathrm{NaOH}$, and biomass loss is minimized by optimizing the hydraulic retention time can result in higher and more economical hydrogen production compared to the process where only one or a few of these factors are controlled at a time.

\section{Acknowledgements}

CRIQ, NSERC, MRI (Quebec-Parana and Quebec-Vietnam) and INRS-ETE Canada have been acknowledged for financial support. The authors are also thankful to "merit scholarship program for foreign students (FQRNT)" for financial assistance to Saurabh Jyoti Sarma.

\section{References}

1 M. Rivarolo, L. Magistri and A. Massardo, Appl. Energy, 2014, 113, 1737-1745.

2 J. Zhou, C. Cheung and C. Leung, Appl. Energy, 2014, 126, 112.

3 N. Saravanan and G. Nagarajan, Appl. Energy, 2010, 87, 22182229.

4 S. Şensöz, D. Angın and S. Yorgun, Biomass Bioenergy, 2000, 19, 271-279.

5 E. B. Sydney, C. Larroche, A. C. Novak, R. Nouaille, S. J. Sarma, S. K. Brar, L. A. J. Letti, V. T. Soccol and C. R. Soccol, Bioresour. Technol., 2014, 159, 380-386.

6 M. E. Nissilä, Y.-C. Li, S.-Y. Wu, C.-Y. Lin and J. A. Puhakka, Appl. Energy, 2012, 100, 58-65.

7 C. Varrone, R. Liberatore, T. Crescenzi, G. Izzo and A. Wang, Appl. Energy, 2013, 105, 349-357.
8 A. A. Kiss and R. M. Ignat, Appl. Energy, 2012, 99, 146-153.

9 D. T. Johnson and K. A. Taconi, Environ. Prog., 2007, 26, 338348.

10 F. Yang, M. A. Hanna and R. Sun, Biotechnol. Biofuels, 2012, $5,13$.

11 S. J. Sarma, S. K. Brar, Y. Le Bihan and G. Buelna, Bioprocess Biosyst. Eng., 2013, 36, 1-10.

12 S. J. Sarma, S. K. Brar, Y. Le Bihan, G. Buelna and C. R. Soccol, J. Chem. Technol. Biotechnol., 2013, 88, 22642271.

$13 \mathrm{http}$ //www.rothsaybiodiesel.ca(accessed on 30/10/2014).

14 P. Bondioli and L. Della Bella, Eur. J. Lipid Sci. Technol., 2005, 107, 153-157.

15 S. J. Sarma, G. S. Dhillon, S. K. Brar, Y. Le Bihan, G. Buelna and M. Verma, Renewable Energy, 2013, 60, 566-571.

16 S. J. Sarma, S. K. Brar, Y. Le Bihan, G. Buelna and C. R. Soccol, Bioresour. Technol., 2014, 151, 49-53.

17 S. Hu, X. Luo, C. Wan and Y. Li, J. Agric. Food Chem., 2012, 60, 5915-5921.

18 J. Thompson and B. He, Appl. Eng. Agric., 2006, 22, 261.

19 S. Roy, M. Vishnuvardhan and D. Das, Appl. Energy, 2014, 136, 51-58.

20 N. Wieczorek, M. A. Kucuker and K. Kuchta, Appl. Energy, 2014, 132, 108-117.

21 T. Ito, Y. Nakashimada, K. Senba, T. Matsui and N. Nishio, J. Biosci. Bioeng., 2005, 100, 260-265.

22 S. W. Van Ginkel and B. Logan, Water Res., 2005, 39, 38193826.

23 T. A. Ngo, M.-S. Kim and S. J. Sim, Int. J. Hydrogen Energy, 2011, 36, 5836-5842.

24 X.-Y. Cheng and C.-Z. Liu, Appl. Energy, 2012, 91, 1-6.

25 R. Datar, J. Huang, P.-C. Maness, A. Mohagheghi, S. Czernik and E. Chornet, Int. J. Hydrogen Energy, 2007, 32, 932-939.

26 M.-L. Zhang, Y.-T. Fan, Y. Xing, C.-M. Pan, G.-S. Zhang and J.-J. Lay, Biomass Bioenergy, 2007, 31, 250-254.

27 P. A. Marques, M. L. Bartolomeu, M. M. Tomé and L. Neves, Bio-hydrogen production from glycerol by a strain of Enterobacter aerogenes, HYPOTHESIS VIII, Lisbon, Portugal, 2009, http://repositorio.lneg.pt/bitstream/10400.9/604/1/ Paula_Marques_HYP_072\%20(4).pdf.

28 http://infopage.gem.wa.gov.au/docs/Price_Schedule_-_Industrial_Gases_49009.xls?(accessed on 17/02/2014).

29 D. Liu, D. Liu, R. J. Zeng and I. Angelidaki, Water Res., 2006, 40, 2230-2236.

30 S. J. Sarma, S. K. Brar, Y. Le Bihan and G. Buelna, Int. J. Hydrogen Energy, 2013, 38, 8704-8707.

31 C.-Y. Chu, B. Sen, C.-H. Lay, Y.-C. Lin and C.-Y. Lin, Appl. Energy, 2012, 100, 10-18.

32 G. Sabourin-Provost and P. C. Hallenbeck, Bioresour. Technol., 2009, 100, 3513-3517.

33 S. Sakai and T. Yagishita, Biotechnol. Bioeng., 2007, 98, 340348.

34 P. A. Selembo, J. M. Perez, W. A. Lloyd and B. E. Logan, Biotechnol. Bioeng., 2009, 104, 1098-1106. 